\title{
MicroRNAs and cancer: Key paradigms in molecular therapy (Review)
}

\author{
WEIGE TAN ${ }^{1,2}$, BODU LIU ${ }^{1}$, SHAOHUA QU ${ }^{1}$, GEHAO LIANG $^{1}$, WEI LUO ${ }^{1}$ and CHANG GONG ${ }^{1}$ \\ ${ }^{1}$ Breast Tumor Center and Guangdong Provincial Key Laboratory of Malignant Tumor Epigenetics and Gene Regulation, \\ Sun Yat-sen Memorial Hospital, Sun Yat-sen University, Guangzhou, Guangdong 510120; ${ }^{2}$ Department of Breast Surgery, \\ The First Affiliated Hospital of Guangzhou Medical University, Guangzhou, Guangdong 510000, P.R. China
}

Received August 2, 2015; Accepted February 7, 2017

DOI: $10.3892 / \mathrm{ol} .2017 .7638$

\begin{abstract}
MicroRNAs (miRNAs) are a type of small non-coding RNA molecule that performs an important role in post-transcriptional gene regulation. Since miRNAs were first identified in 1993, a number of studies have demonstrated that they act as tumor suppressors or oncogenes in human cancer, including colorectal, lung, brain, breast and liver cancer, and leukemia. Large high-throughput studies have previously revealed that miRNA profiling is critical for the diagnosis and prognosis of patients with cancer, while certain miRNAs possess the potential to be used as diagnostic and prognostic biomarkers or therapeutic targets in cancer. The present study reviews the studies and examines the roles of miRNAs in cancer diagnosis, prognosis and treatment, and discusses the potential therapeutic modality of exploiting miRNAs.
\end{abstract}

\section{Contents}

1. Introduction

2. The mechanism of miRNAs in cancer

3. Cancer stem cells

4. Angiogenesis

5. EMT and metastasis

6. Clinical applications of miRNAs

7. Conclusion

Correspondence to: Dr Chang Gong, Breast Tumor Center and Guangdong Provincial Key Laboratory of Malignant Tumor Epigenetics and Gene Regulation, Sun Yat-sen Memorial Hospital, Sun Yat-sen University, 107 Yanjiang West Road, Yuexiu, Guangzhou, Guangdong 510120, P.R. China

E-mail: changgong282@163.com

Key words: microRNAs, epithelial mesenchymal transition, cancer stem cells, treatment

\section{Introduction}

MicroRNAs (miRNAs/miRs) were identified in 1993 (1-3). They are a type of small non-coding RNA, between 19-24 nucleotides in length, which perform a critical role in the regulation of gene expression at the post-transcriptional level. miRNAs act by degrading their RNA targets or by repressing the translation of mRNAs (4). In the previous two decades, numerous studies have indicated the important role of miRNAs in the regulation of crucial cellular processes, including proliferation, differentiation, migration, apoptosis, metabolism and the stress response (5). miRNAs have been demonstrated to act as key regulators in the pathogenesis of diseases (6-11), particularly in cancer.

miRNAs provide a novel insight into the study of cancer. Previously, $>50 \%$ of miRNA genes were revealed to be located in cancer-associated genomic regions and to form central nodal points in cancer development pathways (5), suggesting that miRNAs may perform an important role in the pathogenesis of human cancer. The hypothesis that the dysregulation of miRNAs may perform a fundamental role in the onset, progression and dissemination of numerous types of cancer was primarily confirmed in chronic lymphocytic leukemia (CLL) by Calin et al (12), who demonstrated that miR-15a and miR-16-1 were downregulated or deleted in the majority of patients with CLL.

Uncovering the complex role of miRNAs in cancers presents a challenge. Previous studies revealed that miRNAs regulate a number of molecular pathways of cancer by targeting oncogenes and tumor suppressors in tumorigenesis, cancer maintenance and progression (13), involving biological pathways of cancer-stem-cell biology (14), angiogenesis (15), the epithelial-mesenchymal transition, metastasis (16) and drug resistance (17).

miRNAs are widespread and have been estimated to regulate $>50 \%$ of the human genome $(18,19)$. Results from previous studies revealed that changing the expression of a particular cancer-associated miRNA may alter the expression of a potential oncogenic or anti-oncogenic protein (20), demonstrating that miRNAs may be used as therapeutic targets and tools in cancer treatment.

\section{The mechanism of miRNAs in cancer}

miRNAs overexpressed in cancers were considered to be oncogenes, termed 'oncomirs', which may promote tumor 
development by negatively regulating genes, generally those controlling cell differentiation or apoptosis and/or tumor suppressor genes. A certain number of oncomirs exist in the tumor genome, but only a few of them have been well characterized, including miR-21 (21) and the cluster miR-17-92 (22,23).

miR-21 is overexpressed in breast, colorectal, lung and pancreatic cancer, glioblastoma, neuroblastoma, leukemia and lymphoma. miR-21 affects proliferation, apoptosis, migration, invasion and maintenance of cancer cells in vitro, and is associated with survival of cancer patients in vivo by targeting a tumor-suppressor (21). The miR-17-92 cluster located at chromosome $13 \mathrm{q} 31$ is a polycistronic transcript consisting of miRNAs 17, 18a, 19a, 20a, 19b-1 and 92a-1, It is significantly overexpressed in lung cancer and lymphoma $(22,23)$. V-myc avian myelocytomatosis viral oncogene homolog (c-Myc) activates and regulates the miR-17-92 cluster to modulate E2F1 expression and inhibit c-Myc-induced apoptosis through tumor protein 553 pathway (24). Additionally, miR-17-92 inhibits the tumor suppressor genes phosphatase and tensin homolog (25) and RB2 (26) by activating the protein kinase B signaling pathway to promote cancer-cell survival (Fig. 1). Additionally, oncogenic miR-372 and miR-373 promote cell proliferation and tumor development by targeting the tumor suppressor gene large tumor suppressor kinase 2 (27) and neutralizing inhibition of p53-mediated cyclin-dependent kinase in human testicular germ cell tumors.

The expression of tumor suppressor genes is decreased in cancer cells. Tumor suppressor miRNAs negatively inhibit oncogenes and/or genes that control cell differentiation or apoptosis and thus prevent tumor development. miRNAs let-7 and miR-34 family are known to be tumor suppressor genes.

The expression of let-7 is reduced in a number of types of cancer, and is correlated with poor survival (28). The overexpression of let-7 has been demonstrated to inhibit growth of lung cancer cells in vitro (29). Results from previous studies have revealed that the reduced expression of let-7 increases the protein expression of the pro-oncogene RAS in lung tumors (29-31) (Fig. 1). A loss of expression of miR-34a is associated with metastasis and recurrence in prostate cancer, while restoration of miR-34 expression is associated with clonogenic cell growth and invasion, apoptosis and cellular activation of chemotherapy and radiation in pancreatic cancer. Another study demonstrated that the miR-34 family may regulate the expression and mutation of $\mathrm{p} 53$, while miR-34b and miR-34c target MYC (32-35). A lack of expression of miR-34 family members attenuated p53-dependent and p38-mitogen-activated protein kinase-dependent responses to DNA damage, and led to oncogenesis.

\section{Cancer stem cells}

microRNAs have been demonstrated to perform critical roles in controlling the fate of cancer stem cells (CSCs) $(36,37)$. Numerous genes essential for pluripotency and stem cell function, including Octamer-binding transcription factor 4, NANOG, SRY-Homeobox 2 (SOX2), NOTCH and B-cell lymphoma 2, are targets of miRNAs, such as miR-296, miR-134, miR-470 and the miR-34 family.
The let-7 family, miR-200 family, and miR-30 are all believed to be important for the regulation of breast cancer stem cells. The let-7 family is downregulated in breast-cancer stem cells. Let-7 family members are associated with tumor formation and metastasis of breast cancer in immunocompromised mice by regulating breast CSCs (38). Let-7 results in the loss of self-renewal (RAS silencing) and enhancement of multi-lineage differentiation (high-mobility group AT-hook 2 (HMGA2) silencing) in CSCs by targeting the 3 ' untranslated region (UTR) of RAS and HMGA2 genes (39). The miR-200 family, which comprises miR-200a, miR-200b, miR-200c, miR-141 and miR-429, together with miR-145 and miR-146 is highly downregulated in breast CSCs (40), which undergo epithelial-mesenchymal transition (EMT) in response to transforming growth factor $\beta$ signaling (41). In addition, the stem cell genes SOX2, Krüppel like factor 4, polycomb complex protein BMI-1, polycomb protein Suz12, Zinc finger E-box binding homeobox 1 (ZEB1), and $Z E B 2$ are all targets of miR-200 family members $(42,43)$. A low expression of miR-30 inhibits self-renewal of breast cancer stem cells, while antagonism of miR-30 by antisense oligonucleotides enhances self-renewal, tumor regeneration and metastasis in differentiated breast cancer cells (44) (Fig. 2).

\section{Angiogenesis}

Angiogenesis is essential for tumor growth and metastasis $(45,46)$. Previous studies have demonstrated that miRNAs are able to regulate angiogenesis and tumor cell survival (47-51). The miR-17-92 cluster is significantly upregulated in Myc-induced tumors and overexpressed in Ras cells, where it enhances tumor vessel growth in a paracrine manner (47), exhibiting potent tumor angiogenesis-promoting activity. In ovarian cancer, miR-378 enhances tumor angiogenesis, tumor cell survival and growth by targeting ALCAM and EHD1 (48). The overexpression of let-7f and miR-27b exerts pro-angiogenic effects, as shown by the blockade of angiogenesis with 20-O-methyl oligonucleotide inhibitors in vitro (49). miR-221 and miR-222 inhibit angiogenesis by targeting at least two important regulators of pro-angiogenic endothelial cell function in tumors (50). Repression of the miR-15-16 cluster was found to be associated with advanced tumor stage and poor prognosis in patients with colorectal carcinoma, and is shown to promote tumor angiogenesis and metastasis by the loss of restriction of its target gene, fibroblast growth factor- 2 (FGF2) (51).

\section{EMT and metastasis}

Activation of EMT increases the rates of migration and invasion in tumor cells, while activation of the reverse mesenchymal-to-epithelial transition is required for metastasis outgrowth. Expression of epithelial-cadherin (E-cadherin) by the Cadherin 1 gene is essential for retaining an epithelial cell type (52). EMT transcription factors that serve as E-cadherin repressors- such as zinc finger protein (SNAI)1/SNAI2, basic helix-loop-helix proteins including E47, E2-2, Twist-related protein (TWIST)1/TWIST2, and ZEB1/ZEB2, activate cancer cells by triggering EMT (53). The miR-200 family, miR-27 and 
miR-205 inhibit ZEB1 and ZEB2 (54-56). In breast cancer, the expression of miR-200 is positively correlated with concentrations of E-cadherin. In kidney-derived cells, the restoration of miR-200 expression is sufficient to reverse the transition (mesenchymal-to-epithelial). In pancreatic epithelial cells, the expression of miR-30 family members is inversely correlated with the mesenchymal phenotype (57). In mesenchymal-like ovarian cancer cell lines, an overexpression of miR-429 reverses EMT (58).

\section{Clinical applications of miRNAs}

miRNAs as diagnostic indicators. Numerous tumor-profiling studies have been conducted over the previous 5 years. Several miRNA expression signatures have been identified, which may be used to differentiate between malignant and benign conditions in several organs by screening resected tumors and biopsy samples (59). In leukemia, a 4-miRNA signature was able to differentially diagnose acute lymphoblastic leukemia from acute myeloid leukemia with a sensitivity and specificity of up to $100 \%$ (60). In breast cancer, a 97-gene expression profile has been demonstrated to be an improved method for the classification of breast cancer histological grade compared with lymph-node status and tumor size (61). In pancreatic ductal adenocarcinomas, a signature of 7 differentially expressed miRNAs may provide a more accurate diagnosis compared with conventional cytology (62).

miRNAs as prognostic indicators. miRNA expression patterns have been identified to predict the outcome and prognosis of cancer in several studies. In breast cancer, 31 miRNAs were demonstrated to be significantly associated with clinical factors, while the overexpression of 17 miRNAs was associated with estrogen-receptor-positive stage I or II breast cancer, with good clinical outcome (63). The overexpression of miR-210 is associated with an increased risk of recurrence and a reduced chance of relapse-free survival (64). miR-155 overexpression exhibits an association with poor post-operative survival in lung cancer and B cell lymphomas $(65,66)$. miR-183 family, miR-183, miR-182 and miR-96 expression has been revealed to correlate with the progression of non-small-cell lung cancer (67). miR-200c expression has been associated with overall survival subsequent to surgery in colorectal cancer (68). According to prognosis, 13 miRNAs were identified with variable expression in CLL.

miRNAs and cancer treatment. MicroRNAs possess the capacity to target between tens and hundreds of genes simultaneously. They perform a key role in tumorigenesis as important modulators in cellular pathways by regulating target gene expression through translation repression or mRNA degradation. Thus, miRNAs are attractive candidates for prognostic biomarkers and therapeutic targets in cancer. The identification of miRNAs and their targets is essential for cancer development and metastasis, and therefore may provide exciting therapeutic opportunities. In the present review, potential target genes and a possible mechanism of tumorigenic miRNAs are summarized (69-92) (Table I).

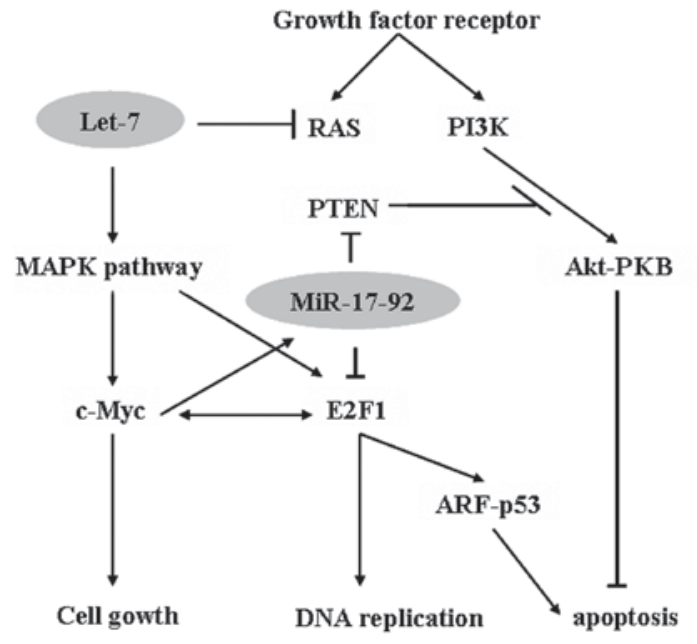

Figure 1. Interaction of miRNAs as oncogenic and tumor suppressor. let-7 suppresses translation of the Ras GTPase genes. The downregulation of let-7 promotes the cell cycle through the Ras-MAPK pathway. miR-17-92 may prohibit oncogene-induced apoptosis. PTEN, phosphatase and tensin homolog; PI3K, phosphoinositide-3 kinase; PKB, protein kinase B; MAPK, mitogen-activated protein kinase; ARF, alternative reading frame protein of p16INK4a locus. miRNA/miR, microRNA; p53, tumor protein 53; E2F1, transcription factor $\mathrm{E} 2 \mathrm{~F} 1$; Akt, RAC- $\alpha$ serine/threonine-protein kinase.

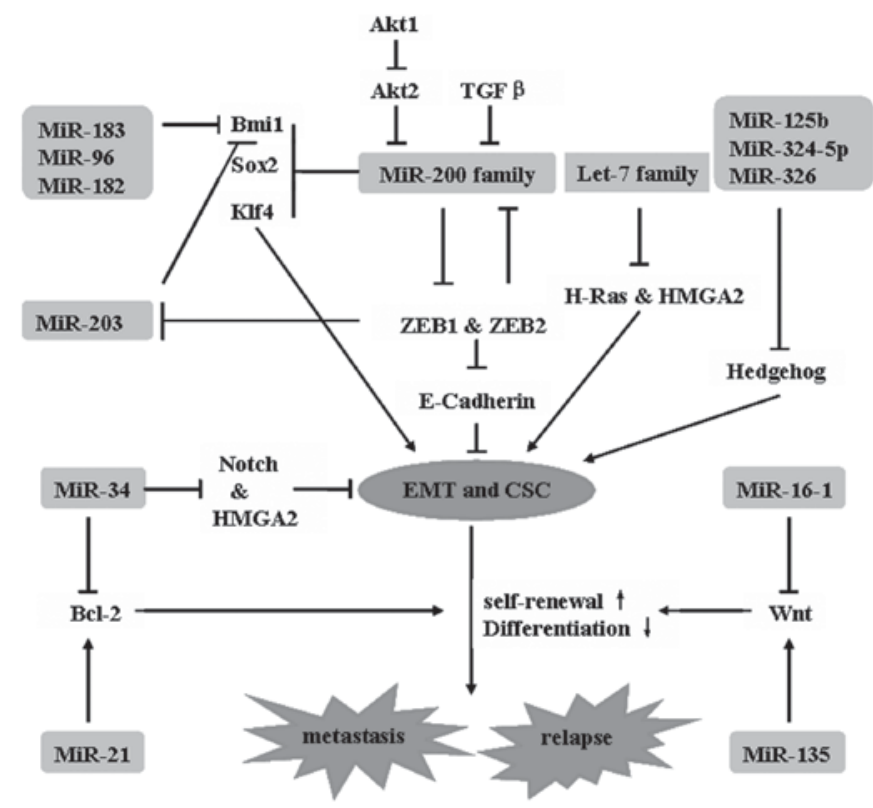

Figure 2. miRNAs associated to breast cancer stem cells and their potential mechanisms. These miRNAs regulate target genes that are involved in the processes of stem cells. The abnormal expression of these potential 'stem cell miRNAs' in cancer indicates that deregulated stem cell genes lead to an increase in the level of self-renewal and a reduction in the intracellular levels of apoptosis in cancer stem cells. This leads to the progression of the cancer. CSC, cancer stem cells; EMT, epithelial-mesenchymal transition; HMGA2, high-mobility group AT-hook 2; Akt1, RAC- $\alpha$ serine/threonine-protein kinase; Akt2; RAC- $\beta$ serine/threonine-protein kinase; TGF- $\beta$, transforming growth factor $\beta$; miRNA/miR, microRNA; Klf4, Krüppel like factor 4; BMI-1, polycomb complex protein BMI-1; ZEB1/2, Zinc finger E-box binding homeobox 1/2; H-Ras, transforming protein p21; Bcl2, B-cell lymphoma 2; E-cadherin, epithelial cadherin.

There are several acknowledged approaches to miRNA targeting: Anti-miRNA oligonucleotides (AMOs) are single-stranded molecules that form direct complementarity 


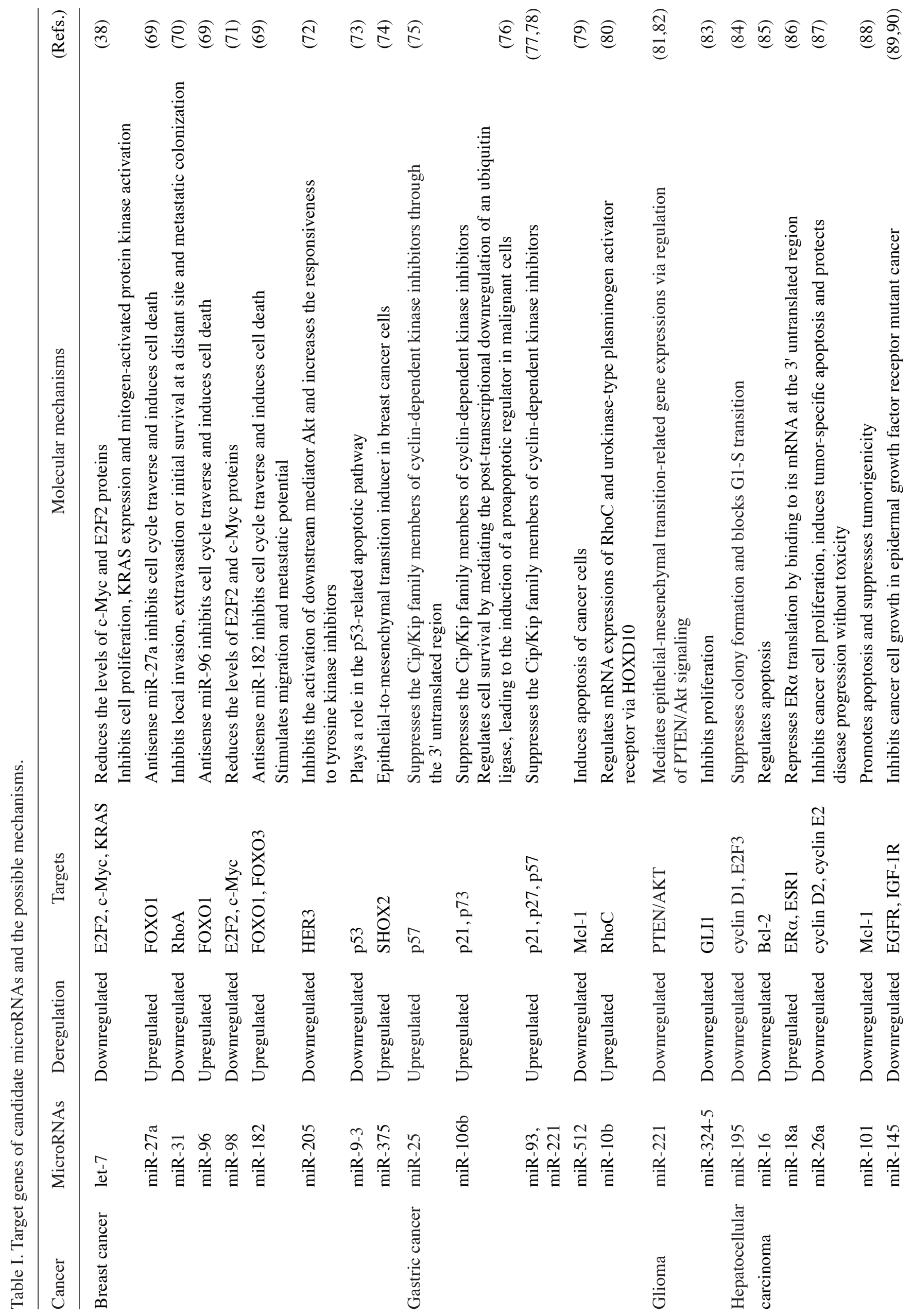


and thus inhibit specific miRNAs. Previous studies have widely used AMOs to target mRNAs and evaluate gene function in vitro and in vivo $(93,94)$. The chemical modification of the AMOs may improve the hybridization affinity of the target RNA in vitro (95), make it resistant to nuclease degradation and activate RNase or other proteins (96). For in vivo delivery, altering the protein binding properties of AMOs is necessary to delay plasma clearance and promote uptake into tissues $(97,98)$. AntagomiRs are single-stranded molecules that form complementarity to miRNAs; however, in order to maintain stability while minimizing degradation, they may also be modified with a cholesterol conjugated 20-O-methyl $(99,100)$. Locked nucleic acids (LNAs) have a methylene bridge to functionally lock ribose conformation, which consequently leads to increased binding affinity and stability (101). miRNA sponges function by using multiple complementary 3'UTR mRNA sites for a specific miRNA (102). These sponges competitively bind to miRNA, thus interfering with the normal targeting of a single miRNA by targeting it with antisense oligonucleotides. In addition, the development of stable sponges may assist in recapitulating the effects of downregulation of aberrantly expressed miRNAs (103-105) and nanoparticles, the formulations of which may be used primarily for in vitro delivery of miRNAs $(106,107)$.

A small number of studies at present have used this technology for miRNA delivery (108). The results of previous studies demonstrated that by using liposome polycation-hyaluronic acid particles as a carrier for miRNA modified with a tumor targeting monoclonal antibody, a golgin candidate 4 single-chain variable fragment, they were able to target lung metastases in a murine model of metastatic melanoma $(109,110)$.

\section{Conclusion}

In conclusion, miRNAs have changed our understanding of gene expression and set a precedent for the development of novel diagnostic methods and treatments for cancer. To translate these data into clinical application, large cohort studies are required to examine the prognostic and diagnostic value of miRNA panels. In the long term, it is important to identify additional potential targets of miRNA, and to develop safe and specific methods to deliver miRNA-based treatments in order to make the modulation of miRNAs a critical technique for cancer treatment and management.

\section{Acknowledgements}

This study was supported by grants from the National Key Research and Development Program of China (no. 2017YFC1309100); the Natural Science Foundation of China (nos. 81772836, 81472466 and 81672594); National Science Foundation of Guangdong Province (nos. 2017A030313554, 2014A03036003, 2014A030310378, 2014A020212059, 2015A030313172, 2015B050501004, 2016A050502018 and 2016A030313237); China Scholarship Council (no. 201606385034); Cultivation for Major Projects and Emerging Interdisciplinary Funding Project of Sun Yat-sen University (no. 17ykjc13) and Elite Young Scholars Program of Sun Yat-sen Memorial Hospital (no. Y201401). 


\section{References}

1. Lee RC, Feinbaum RL and Ambros V: The c. elegans heterochronic gene lin-4 encodes small RNAs with antisense complementarity to lin-14. Cell 75: 843-854, 1993.

2. Carrington JC and Ambros V: Role of microRNAs in plant and animal development. Science 301: 336-338, 2003.

3. Huang JC, Babak T, Corson TW, Chua G, Khan S, Gallie BL, Hughes TR, Blencowe BJ, Frey BJ and Morris QD: Using expression profiling data to identify human microRNA targets. Nat Methods 4: 1045-1049, 2007.

4. Mattick JS and Gagen MJ: The evolution of controlled multitasked gene networks: The role of introns and other noncoding RNAs in the development of complex organisms. Mol Biol Evol 18: 1611-1630, 2001.

5. Di Leva G, Garofalo M and Croce CM: MicroRNAs in cancer. Annu Rev Pathol 9: 287-314, 2014

6. Plank M, Maltby S, Mattes J and Foster PS: Targeting translational control as a novel way to treat inflammatory disease: The emerging role of MicroRNAs. Clin Exp Allergy 43: 981-999, 2013.

7. Fernández-Hernando C, Ramírez CM, Goedeke L and Suárez Y: MicroRNAs in metabolic disease. Arterioscler Thromb Vasc Biol 33: 178-185, 2013.

8. Wang W, Kwon EJ and Tsai LH: MicroRNAs in learning, memory, and neurological diseases. Learn Mem 19: 359-368, 2012.

9. Tao G and Martin JF: MicroRNAs get to the heart of development. Elife 2: e01710, 2013

10. Menghini R, Stöhr R and Federici M: MicroRNAs in vascular aging and atherosclerosis. Ageing Res Rev 17: 68-78, 2014.

11. Timoneda O, Núñez-Hernández F, Balcells I, Muñoz M, Castelló A, Vera G, Pérez LJ, Egea R, Mir G, Córdoba S, et al: The role of viral and host microRNAs in the Aujeszky's disease virus during the infection process. PLoS One 9: e86965, 2014.

12. Calin GA, Dumitru CD, Shimizu M, Bichi R, Zupo S, Noch E, Aldler H, Rattan S, Keating M, Rai K, et al: Frequent deletions and down-regulation of micro- RNA genes miR15 and miR16 at $13 q 14$ in chronic lymphocytic leukemia. Proc Natl Acad Sci USA 99: 15524-15529, 2002.

13. Zhang B, Pan X, Cobb GP and Anderson TA: microRNAs as oncogenes and tumor suppressors. Dev Biol 302: 1-12, 2007.

14. Leal JA, Feliciano A and Lleonart ME: Stem cell microRNAs in senescence and immortalization: Novel players in cancer therapy. Med Res Rev 33: 112-138, 2013.

15. Anand S: A brief primer on microRNAs and their roles in angiogenesis. Vasc Cell 5: 2, 2013.

16. Ding XM: MicroRNAs: Regulators of cancer metastasis and epithelial-mesenchymal transition (EMT). Chin J Cancer 33: 140-147, 2014.

17. Raza U, Zhang JD and Sahin O: MicroRNAs: Master regulators of drug resistance, stemness, and metastasis. J Mol Med (Berl) 92: 321-336, 2014.

18. Friedman RC, Farh KK, Burge CB and Bartel DP: Most mammalian mRNAs are conserved targets of microRNAs. Genome Res 19: 92-105, 2009.

19. Spengler RM, Oakley CK and Davidson BL: Functional microRNAs and target sites are created by lineage-specific transposition. Hum Mol Genet 23: 1783-1793, 2014.

20. Carthew RW and Sontheimer EJ: Origins and Mechanisms of miRNAs and siRNAs. Cell 136: 642-655, 2009.

21. Selcuklu SD, Donoghue MT and Spillane C: $\operatorname{miR}-21$ as a key regulator of oncogenic processes. Biochem Soc Trans 37: 918-925, 2009

22. Zhang ZW, An Y and Teng CB: The roles of miR-17-92 cluster in mammal development and tumorigenesis. Yi Chuan 31: 1094-1100, 2009 (In Chinese).

23. Osada H and Takahashi T: let-7 and miR-17-92: Small-sized major players in lung cancer development. Cancer Sci 102: 9-17, 2011.

24. Rinaldi A, Poretti G, Kwee I, Zucca E, Catapano CV, Tibiletti MG and Bertoni F: Concomitant MYC and microRNA cluster miR-17-92 (C13orf25) amplification in human mantle cell lymphoma. Leuk Lymphoma 48: 410-412, 2007.

25. Shuang T, Shi C, Chang S, Wang M and Bai CH: Downregulation of miR-17\&\#126;92 expression increase paclitaxel sensitivity in human ovarian carcinoma SKOV3-TR30 cells via BIM instead of PTEN. Int J Mol Sci 14: 3802-3816, 2013.
26. Shuang T, Shi $C$, Chang $S$, Wang $M$ and Bai $C H$ : miR-17-92 cluster accelerates adipocyte differentiation by negatively regulating tumor-suppressor Rb2/p130. Proc Natl Acad Sci USA 105: 2889-2894, 2008.

27. Cho WJ, Shin JM, Kim JS, Lee MR, Hong KS, Lee JH, Koo KH, Park JW and Kim KS: miR-372 regulates cell cycle and apoptosis of ags human gastric cancer cell line through direct regulation of LATS2. Mol Cells 28: 521-527, 2009.

28. Boyerinas B, Park SM, Hau A, Murmann AE and Peter ME: The role of let-7 in cell differentiation and cancer. Endocr Relat Cancer 17: F19-F36, 2010.

29. He XY, Chen JX, Ou-Yang X, Zhang Z and Peng HM: Construction of let-7a expression plasmid and its inhibitory effect on k-Ras protein in A549 lung cancer cells. Nan Fang Yi Ke Da Xue Xue Bao 30: 2427-2431, 2010 (In Chinese).

30. Wang YY, Ren T, Cai YY and He XY: MicroRNA let-7a inhibits the proliferation and invasion of nonsmall cell lung cancer cell line $95 \mathrm{D}$ by regulating K-Ras and HMGA2 gene expression. Cancer Biother Radiopharm 28: 131-137, 2013

31. Xia XM, Jin WY, Shi RZ, Zhang YF and Chen J: Clinical significance and the correlation of expression between Let-7 and K-ras in non-small cell lung cancer. Oncol Lett 1: 1045-1047, 2010.

32. Okada N, Lin CP, Ribeiro MC, Biton A, Lai G, He X, Bu P, Vogel H, Jablons DM, Keller AC, et al: A positive feedback between p53 and miR-34 miRNAs mediates tumor suppression. Genes Dev 28: 438-450, 2014.

33. Cheng CY, Hwang CI, Corney DC, Flesken-Nikitin A, Jiang L, Oner GM, Munroe RJ, Schimenti JC, Hermeking H and Nikitin AY: miR-34 cooperates with p53 in suppression of prostate cancer by joint regulation of stem cell compartment. Cell Rep 6: 1000-1007, 2014.

34. Ji Q, Hao X, Zhang M, Tang W, Yang M, Li L, Xiang D, Desano JT, Bommer GT, Fan D, et al: MicroRNA miR-34 inhibits human pancreatic cancer tumor-initiating cells. PLoS One 4: e6816, 2009.

35. Cannell IG and Bushell M: Regulation of Myc by miR-34c: A mechanism to prevent genomic instability? Cell Cycle 9: 2726-2730, 2010.

36. Shah M and Allegrucci C: Stem cell plasticity in development and cancer: Epigenetic origin of cancer stem cells. Subcell Biochem 61: 545-565, 2013.

37. Lerner RG and Petritsch C: A microRNA-operated switch of asymmetric-to-symmetric cancer stem cell divisions. Nat Cell Biol 16: 212-214, 2014

38. Sun X, Fan C, Hu LJ, Du N, Xu CW and Ren H: Role of let-7 in maintaining characteristics of breast cancer stem cells. Xi Bao Yu Fen Zi Mian Yi Xue Za Zhi 28: 789-792, 2012.

39. Chen KJ, Hou Y, Wang K, Li J, Xia Y, Yang XY, Lv G, Xing XL and Shen F: Reexpression of Let-7 g microRNA inhibits the proliferation and migration via K-Ras/HMGA2/snail axis in hepatocellular carcinoma. Biomed Res Int 2014: 742417, 2014.

40. Lim YY, Wright JA, Attema JL, Gregory PA, Bert AG, Smith E, Thomas D, Lopez AF, Drew PA, Khew-Goodall Y and Goodall GJ: Epigenetic modulation of the miR-200 family is associated with transition to a breast cancer stem-cell-like state. J Cell Sci 126: 2256-2266, 2013.

41. Gibbons DL, Lin W, Creighton CJ, Rizvi ZH, Gregory PA, Goodall GJ, Thilaganathan N, Du L, Zhang Y, Pertsemlidis A and Kurie JM: Contextual extracellular cues promote tumor cell EMT and metastasis by regulating miR-200 family expression. Genes Dev 23: 2140-2151, 2009.

42. Truong HH, Xiong J, Ghotra VP, Nirmala E, Haazen L, Le Dévédec SE, Balcioğlu HE, He S, Snaar-Jagalska BE, Vreugdenhil E, et al: $\beta 1$ integrin inhibition elicits a prometastatic switch through the TGF $\beta$-miR-200-ZEB network in E-cadherin-positive triple-negative breast cancer. Sci Signal 7: ra15, 2014.

43. Iliopoulos D, Lindahl-Allen M, Polytarchou C, Hirsch HA, Tsichlis PN and Struhl K: Loss of miR-200 inhibition of Suz12 leads to polycomb-mediated repression required for the formation and maintenance of cancer stem cells. Mol Cell 39: 761-772, 2010.

44. Ouzounova M, Vuong T, Ancey PB, Ferrand M, Durand G, Le-Calvez Kelm F, Croce C, Matar C, Herceg Z and Hernandez-Vargas H: MicroRNA miR-30 family regulates non-attachment growth of breast cancer cells. BMC Genomics 14: 139, 2013.

45. Samples J, Willis M and Klauber-Demore N: Targeting angiogenesis and the tumor microenvironment. Surg Oncol Clin N Am 22: 629-639, 2013. 
46. Pasquier E, Andre N, Trahair T and Kavallaris M: Reply: Comment on 'Beta-blockers increase response to chemotherapy via direct anti-tumour and anti-angiogenic mechanisms in neuroblastoma'- $\beta$-blockers are potent anti-angiogenic and chemo-sensitising agents, rather than cytotoxic drugs. $\mathrm{Br}$ J Cancer 109: 2024-2025, 2013.

47. Kuhnert $\mathrm{F}$ and Kuo CJ: miR-17-92 angiogenesis micromanagement. Blood 115: 4631-4633, 2010.

48. Chan JK, Kiet TK, Blansit K, Ramasubbaiah R, Hilton JF, Kapp DS and Matei D: MiR-378 as a biomarker for response to anti-angiogenic treatment in ovarian cancer. Gynecol Oncol 133: 568-574, 2014.

49. Melo SA and Kalluri R: Angiogenesis is controlled by miR-27b associated with endothelial tip cells. Blood 119: 2439-2440, 2012.

50. Santhekadur PK, Das SK, Gredler R, Chen D, Srivastava J, Robertson C,Baldwin AS Jr, Fisher PB and SarkarD: Multifunction protein staphylococcal nuclease domain containing 1 (SND1) promotes tumor angiogenesis in human hepatocellular carcinoma through novel pathway that involves nuclear factor $\mathrm{\kappa B}$ and miR-221. J Biol Chem 287: 13952-13958, 2012.

51. Xue G, Yan HL, Zhang Y, Hao LQ, Zhu XT, Mei Q and Sun SH: c-Myc-mediated repression of miR-15-16 in hypoxia is induced by increased HIF-2 $\alpha$ and promotes tumor angiogenesis and metastasis by upregulating FGF2. Oncogene 34: 1393-1406, 2015.

52. Liu YY, Han JY, Lin SC, Liu ZY and Jiang WT: Effect of CDH1 gene methylation on transforming growth factor (TGF- $\beta$ )-induced epithelial-mesenchymal transition in alveolar epithelial cell line A549. Genet Mol Res 13: 8568-8576, 2014.

53. Garg M: Epithelial-mesenchymal transition - activating transcription factors - multifunctional regulators in cancer. World J Stem Cells 5: 188-195, 2013.

54. Park SM, Gaur AB, Lengyel E and Peter ME: The miR-200 family determines the epithelial phenotype of cancer cells by targeting the E-cadherin repressors ZEB1 and ZEB2. Genes Dev 22: 894-907, 2008.

55. Young JA, Ting KK, Li J, Moller T, Dunn L, Lu Y, Moses J, Prado-Lourenço L, Khachigian LM, Ng M, et al: Regulation of vascular leak and recovery from ischemic injury by general and VE-cadherin-restricted miRNA antagonists of miR-27. Blood 122: 2911-2919, 2013.

56. Tellez CS, Juri DE, Do K, Bernauer AM, Thomas CL Damiani LA, Tessema M, Leng S and Belinsky SA: EMT and stem cell-like properties associated with miR-205 and miR-200 epigenetic silencing are early manifestations during carcinogen-induced transformation of human lung epithelial cells. Cancer Res 71: 3087-3097, 2011.

57. Zhang J, Zhang H, Liu J, Tu X, Zang Y, Zhu J, Chen J, Dong L and Zhang J: miR-30 inhibits TGF- $\beta 1$-induced epithelial-to-mesenchymal transition in hepatocyte by targeting Snail1. Biochem Biophys Res Commun 417: 1100-1105, 2012.

58. Chen J, Wang L, Matyunina LV, Hill CG and McDonald JF: Overexpression of miR-429 induces mesenchymal-to-epithelial transition (MET) in metastatic ovarian cancer cells. Gynecol Oncol 121: 200-205, 2011.

59. Stahlhut $C$ and Slack FJ: MicroRNAs and the cancer phenotype: Profiling, signatures and clinical implications. Genome Med 5: 111,2013

60. de Leeuw DC, van den Ancker W, Denkers F, de Menezes RX, Westers TM, Ossenkoppele GJ, van de Loosdrecht AA and Smit L: MicroRNA profiling can classify acute leukemias of ambiguous lineage as either acute myeloid leukemia or acute lymphoid leukemia. Clin Cancer Res 19: 2187-2196, 2013.

61. Sun YF, Leu JD, Chen SM, Lin IF and Lee YJ: Results based on 124 cases of breast cancer and 97 controls from Taiwan suggest that the single nucleotide polymorphism (SNP309) in the MDM2 gene promoter is associated with earlier onset and increased risk of breast cancer. BMC Cancer 9: 13, 2009.

62. Bolmeson C, Esguerra JL, Salehi A, Speidel D, Eliasson L and Cilio CM: Differences in islet-enriched miRNAs in healthy and glucose intolerant human subjects. Biochem Biophys Res Commun 404: 16-22, 2011.

63. Wee EJ, Peters K, Nair SS, Hulf T, Stein S, Wagner S, Bailey P, Lee SY, Qu WJ, Brewster B, et al: Mapping the regulatory sequences controlling 93 breast cancer-associated miRNA genes leads to the identification of two functional promoters of the Hsa-mir-200b cluster, methylation of which is associated with metastasis or hormone receptor status in advanced breast cancer. Oncogene 31: 4182-4195, 2012.
64. Rothé F, Ignatiadis M, Chaboteaux C, Haibe-Kains B, Kheddoumi N, Majjaj S, Badran B, Fayyad-Kazan H, Desmedt C, Harris AL, et al: Global microRNA expression profiling identifies MiR-210 associated with tumor proliferation, invasion and poor clinical outcome in breast cancer. PLoS One 6: e20980, 2011.

65. Yang M, Shen H, Qiu C, Ni Y, Wang L, Dong W, Liao Y and Du J: High expression of miR-21 and miR-155 predicts recurrence and unfavourable survival in non-small cell lung cancer. Eur J Cancer 49: 604-615, 2013.

66. Eis PS, Tam W, Sun L, Chadburn A, Li Z, Gomez MF, Lund E and Dahlberg JE: Accumulation of miR-155 and BIC RNA in human B cell lymphomas. Proc Natl Acad Sci USA 102: 3627-3632, 2005.

67. Zhu J, Feng Y, Ke Z, Yang Z, Zhou J, Huang X and Wang L: Down-regulation of miR-183 promotes migration and invasion of osteosarcoma by targeting Ezrin. Am J Pathol 180: 2440-2451, 2012.

68. Toiyama Y, Hur K, Tanaka K, Inoue Y, Kusunoki M, Boland CR and Goel A: Serum miR-200c is a novel prognostic and metastasis-predictive biomarker in patients with colorectal cancer. Ann Surg 259: 735-743, 2014.

69. Guttilla IK and White BA: Coordinate regulation of FOXO1 by miR-27a, miR-96, and miR-182 in breast cancer cells. J Biol Chem 284: 23204-23216, 2009.

70. Viré E, Curtis C, Davalos V, Git A, Robson S, Villanueva A, Vidal A, Barbieri I, Aparicio S, Esteller M, et al: The breast cancer oncogene EMSY represses transcription of antimetastatic microRNA miR-31. Mol Cell 53: 806-818, 2014.

71. Deng ZQ, Yin JY, Tang Q, Liu FQ, Qian J, Lin J, Shao R, Zhang $\mathrm{M}$ and He L: Over-expression of miR-98 in FFPE tissues might serve as a valuable source for biomarker discovery in breast cancer patients. Int J Clin Exp Pathol 7: 1166-1171, 2014.

72. Wu H and Mo YY: Targeting miR-205 in breast cancer. Expert Opin Ther Targets 13: 1439-1448, 2009.

73. Li X, Xie W, Xie C, Huang C, Zhu J, Liang Z, Deng F, Zhu M, Zhu W,Wu R, et al: Curcumin modulates miR-19/PTEN/AKT/p53 Axis to suppress bisphenol a-induced MCF-7 breast cancer cell proliferation. Phytother Res 28: 1553-1560, 2014.

74. Hong S, Noh H, Teng Y, Shao J, Rehmani H, Ding HF, Dong Z, Su SB, Shi H, Kim J and Huang S: SHOX2 Is a direct miR-375 target and a novel epithelial-to-mesenchymal transition inducer in breast cancer cells. Neoplasia 16: 279-290, 2014

75. Zhao H, Wang Y, Yang L, Jiang R and Li W: MiR-25 promotes gastric cancer cells growth and motility by targeting RECK. Mol Cell Biochem 385: 207-213, 2014.

76. Ivanovska I, Ball AS, Diaz RL, Magnus JF, Kibukawa M, Schelter JM, Kobayashi SV, Lim L, Burchard J, Jackson AL, et al: MicroRNAs in the miR-106b family regulate $\mathrm{p} 21 / \mathrm{CDKN} 1 \mathrm{~A}$ and promote cell cycle progression. Mol Cell Biol 28: 2167-2174, 2008.

77. Choi OR and Lim IK: Loss of p21(Sdi1) expression in senescent cells after DNA damage accompanied with increase of miR-93 expression and reduced p53 interaction with p21 (Sdi1) gene promoter. Biochem Biophys Res Commun 407: 406-411, 2011.

78. Sarkar S, Dubaybo H, Ali S, Goncalves P, Kollepara SL, Sethi S, Philip PA and Li Y: Down-regulation of miR-221 inhibits proliferation of pancreatic cancer cells through up-regulation of PTEN, p27(kip1), p57(kip2) and PUMA. Am J Cancer Res 3: 465-477, 2013.

79. Kurashina R, Kikuchi K, Iwaki J, Yoshitake H, Takeshita T and Takizawa T: Placenta-specific miRNA (miR-512-3p) targets PPP3R1 encoding the calcineurin B regulatory subunit in BeWo cells. J Obstet Gynaecol Res 40: 650-660, 2014.

80. Liu Z, Zhu J, Cao H, Ren H and Fang X: miR-10b promotes cell invasion through RhoC-AKT signaling pathway by targeting HOXD10 in gastric cancer. Int J Oncol 40: 1553-1560, 2012.

81. Papagiannakopoulos T, Friedmann-Morvinski D, Neveu P, Dugas JC, Gill RM, Huillard E, Liu C, Zong H, Rowitch DH, Barres BA, et al: Pro-neural miR-128 is a glioma tumor suppressor that targets mitogenic kinases. Oncogene 31: 1884-1895, 2012.

82. Xie Q, Huang Z, Yan Y, Li F and Zhong X: miR-221 mediates epithelial-mesenchymal transition-related gene expressions via regulation of PTEN/Akt signaling in drug-resistant glioma cells. Nan Fang Yi Ke Da Xue Xue Bao 34: 218-222, 2014 (In Chinese)

83. Xu HS, Zong HL, Shang M, Ming X, Zhao JP, Ma C and Cao L: MiR-324-5p inhibits proliferation of glioma by target regulation of GLI1. Eur Rev Med Pharmacol Sci 18: 828-832, 2014. 
84. Yang X, Yu J, Yin J, Xiang Q, Tang H and Lei X: MiR-195 regulates cell apoptosis of human hepatocellular carcinoma cells by targeting LATS2. Pharmazie 67: 645-651, 2012.

85. Tsang TY, Tang WY, Chan JY, Co NN, Au Yeung CL, Yau PL, Kong SK, Fung KP and Kwok TT: P-glycoprotein enhances radiation-induced apoptotic cell death through the regulation of miR-16 and Bcl-2 expressions in hepatocellular carcinoma cells. Apoptosis 16: 524-535, 2011.

86. Li L, Guo Z, Wang J, Mao Y and Gao Q: Serum miR-18a: A potential marker for hepatitis B virus-related hepatocellular carcinoma screening. Dig Dis Sci 57: 2910-2916, 2012.

87. Zhang Y, Zhang B, Zhang A, Li X, Liu J, Zhao J, Zhao Y, Gao J, Fang D and Rao Z: IL-6 upregulation contributes to the reduction of miR-26a expression in hepatocellular carcinoma cells. Braz $\mathrm{J}$ Med Biol Res 46: 32-38, 2013.

88. Sheng Y, Li J, Zou C, Wang S, Cao Y, Zhang J, Huang A and Tang H: Downregulation of miR-101-3p by hepatitis B virus promotes proliferation and migration of hepatocellular carcinoma cells by targeting Rab5a. Arch Virol 159: 2397-2410, 2014.

89. Yang XW, Zhang LJ, Huang XH, Chen LZ, Su Q, Zeng WT, Li W and Wang Q: miR-145 suppresses cell invasion in hepatocellular carcinoma cells: MiR-145 targets ADAM17. Hepatol Res 44: 551-559, 2014

90. Law PT, Ching AK, Chan AW, Wong QW, Wong CK, To KF and Wong N: MiR-145 modulates multiple components of the insulin-like growth factor pathway in hepatocellular carcinoma. Carcinogenesis 33: 1134-41, 2012.

91. Epis MR, Giles KM, Barker A, Kendrick TS and Leedman PJ: miR-331-3p regulates ERBB-2 expression and androgen receptor signaling in prostate cancer. J Biol Chem 284: 24696-24704, 2009.

92. Liu YN, Yin JJ, Abou-Kheir W, Hynes PG, Casey OM, Fang L, Yi M, Stephens RM, Seng V, Sheppard-Tillman H, et al: MiR-1 and miR-200 inhibit EMT via Slug-dependent and tumorigenesis via Slug-independent mechanisms. Oncogene 32: 296-306, 2013.

93. Weiler J, Hunziker J and Hall J: Anti-miRNA oligonucleotides (AMOs): Ammunition to target miRNAs implicated in human disease? Gene Ther 13: 496-502, 2006.

94. Baigude $\mathrm{H}$ and Rana TM: Strategies to antagonize miRNA functions in vitro and in vivo. Nanomedicine (Lond) 9: 2545-2555, 2014.

95. Lennox KA and Behlke MA: Chemical modification and design of anti-miRNA oligonucleotides. Gene Ther 18: 1111-1120, 2011.

96. Gaglione M, Milano G, Chambery A, Moggio L, Romanelli A and Messere A: PNA-based artificial nucleases as antisense and anti-miRNA oligonucleotide agents. Mol Biosyst 7: 2490-2499, 2011.

97. Kim JH, Yeom JH, Ko JJ, Han MS, Lee K, Na SY and Bae J: Effective delivery of anti-miRNA DNA oligonucleotides by functionalized gold nanoparticles. J Biotechnol 155: 287-292, 2011.
98. Rayner KJ, Esau CC, Hussain FN, McDaniel AL, Marshall SM, van Gils JM, Ray TD, Sheedy FJ, Goedeke L, Liu X, et al: Inhibition of $\mathrm{miR}-33 \mathrm{a} / \mathrm{b}$ in non-human primates raises plasma HDL and lowers VLDL triglycerides. Nature 478: 404-407, 2011.

99. Ziegler S, Eberle ME, Wölfle SJ, Heeg K and Bekeredjian-Ding I: Bifunctional oligodeoxynucleotide/antagomiR constructs: Evaluation of a new tool for microRNA silencing. Nucleic Acid Ther 23: 427-434, 2013

100. Velu CS and Grimes HL: Utilizing antagomiR (antisense microRNA) to knock down microRNA in murine bone marrow cells. Methods Mol Biol 928: 185-195, 2012.

101. Chabot S, Orio J, Castanier R, Bellard E, Nielsen SJ, Golzio M and Teissié J: LNA-based oligonucleotide electrotransfer for miRNA inhibition. Mol Ther 20: 1590-1598, 2012.

102. Kluiver J, Slezak-Prochazka I, Smigielska-Czepiel K, Halsema N, Kroesen BJ and van den Berg A: Generation of miRNA sponge constructs. Methods 58: 113-117, 2012.

103. Niu WY, Wu SQ, Xu ZZ, Lin J and Zhan R: Anti-leukemia mechanism of miR-17 and miR-20a silencing mediated by miRNA sponge. Zhongguo Shi Yan Xue Ye Xue Za Zhi 22: 932-937, 2014 (In Chinese).

104. Wu SQ, Xu ZZ, Lin J and Zhan R: Construction of miRNA sponge targeting miR-20a and stable expression in Jurkat leukemia cell line. Zhongguo Shi Yan Xue Ye Xue Za Zhi 20: 1056-1062, 2012.

105. de Melo Maia B, Ling H, Monroig P, Ciccone M, Soares FA, Calin GA and Rocha RM: Design of a miRNA sponge for the miR-17 miRNA family as a therapeutic strategy against vulvar carcinoma. Mol Cell Probes 29: 420-426, 2015.

106. Qureshi AT, Monroe WT, Dasa V, Gimble JM and Hayes DJ: miR-148b-nanoparticle conjugates for light mediated osteogenesis of human adipose stromal/stem cells. Biomaterials 34: 7799-7810, 2013.

107. Babar IA, Cheng CJ, Booth CJ, Liang X, Weidhaas JB, Saltzman WM and Slack FJ: Nanoparticle-based therapy in an in vivo microRNA-155 (miR-155)-dependent mouse model of lymphoma. Proc Natl Acad Sci USA 109: E1695-E1704, 2012.

108. Chen Y, Zhu X, Zhang X, Liu B and Huang L: Nanoparticles modified with tumor-targeting scFv deliver siRNA and miRNA for cancer therapy. Mol Ther 18: 1650-1656, 2010.

109. de Campos VE, Teixeira CA, da Veiga VF, Ricci E Jr and Holandino C: L-tyrosine-loaded nanoparticles increase the antitumoral activity of direct electric current in a metastatic melanoma cell model. Int J Nanomedicine 5: 961-971, 2010.

110. Gu J, Chen X, Xin H, Fang X and Sha X: Serum-resistant complex nanoparticles functionalized with imidazole-rich polypeptide for gene delivery to pulmonary metastatic melanoma. Int J Pharm 461: 559-569, 2014. 